\title{
Achieving Adherence in Home-Based Rehabilitation with Novel Human Machine Interactions that Stimulate Community-Dwelling Older Adults
}

\author{
Dimitrios Gatsios, Eleni. I. Georga, Konstantina \\ K. Kourou, Dimitrios I. Fotiadis \\ Unit of Medical Technology and Intelligent Information \\ Systems, Department of Materials Science and Engineering \\ University of Ioannina \\ Ioannina Greece \\ fotiadis@cc.uoi.gr
}

\author{
Matthew Liston, Marousa Pavlou \\ Centre for Human and Applied Physiological Sciences \\ King's College London \\ London United Kingdom \\ Marousa.Pavlou@kcl.ac.uk
}

\begin{abstract}
Balance disorders are expressed with main symptoms of vertigo, dizziness instability and disorientation. Most of them are caused by inner ear pathologies, but neurological, medical and psychological factors are also responsible. Balance disorders overwhelmingly affect daily activities and cause psychological and emotional hardship. They are also the main cause of falls which are a global epidemic. Home based balance rehabilitation is an effective approach for alleviating symptoms and for improving balance and self-confidence. However, the adherence in such programs is usually low with lack of motivation and disease related issues being the most influential factors. Holobalance adopts the Capability, Opportunity and Motivation (COM) and Behaviour (B) model to identify the sources of the behaviour that should be targeted for intervention and proposes specific Information Technology components that provide the identified interventions to the users in order to achieve the target behavioural change, which in this case is adherence to home base rehabilitation.
\end{abstract}

\section{CCS CONCEPTS}

-Human-centered computing---Human computer interaction (HCI)---Interaction paradigms---Mixed / augmented reality

Permission to make digital or hard copies of all or part of this work for personal or classroom use is granted without fee provided that copies are not made or distributed for profit or commercial advantage and that copies bear this notice and the full citation on the first page. Copyrights for components of this work owned by others than the author(s) must be honored. Abstracting with credit is permitted. To copy otherwise, or republish, to post on servers or to redistribute to lists, requires prior specific permission and/or a fee. Request permissions from Permissions@ acm.org.

PETRA '19, June 5-7, 2019, Rhodes, Greece

(C) 2019 Copyright is held by the owner/author(s). Publication rights licensed to ACM.

ACM ISBN 978-1-4503-6232-0/19/06 ..\$15.00

https://doi.org/10.1145/3316782.3322762

\author{
Dimitrios Kikidis, Athanasios Bibas, Christos \\ Nikitas \\ First Department of Otolaryngology-Head and Neck \\ Surgery, 'Hippokrateio' General Hospital \\ National Kapodistrian University of Athens \\ Athens Greece \\ dimitriskikidis@yahoo.com
}

\author{
Doris Eva Bamiou, Sergi Costafreda \\ UCL Ear Institute \& University College London Hospitals \\ Biomedical Research Centre Hearing \& Deafness \\ London United Kingdom \\ d.bamiou@ucl.ac.uk
}

- Applied computing---Life and medical sciences---Health
informatics

\section{KEYWORDS}

Balance disorders, Home-based balance rehabilitation, Virtual coaching, Behavioural modelling

\section{Introduction}

Balance disorders are common, with vestibular related vertigo having a 1 year prevalence $8.4 \%$ [2], while the odds of vestibular dysfunction increase with age, from $>1 / 3$ affected adults over 40 years to $80 \%$ affected in older adult fallers $[1 ; 10]$.

The presence of a vestibular dysfunction together with dizziness increases the odds of falling 12-fold. This is a significant problem, particularly in older adults, since approx. $35 \%$ over 65 who live at home fall annually [21]. $30 \%$ of these falls are due to balance \& gait disorders, vertigo and dizziness with $70 \%$ of falls occurring during gait $[3 ; 17]$. Falls affect the quality of life of older individuals and their significant others and represent a major concern among the elderly $[14 ; 18]$. The societal and healthcare costs are also significant with a reported cost of falls in EU of 25 billion, which is expected to exceed 45 billion Euros by 2050 (EuroSafe 2015) [6]. Concerns such as low confidence and fear of more falls as well as reduced quality of life further add to the problem [16].

Home-based balance and strength training programmes are proven to decrease the rate of falls, as well as better control the risk factors for falls and risk of death $[4 ; 19]$. Such programmes improve 


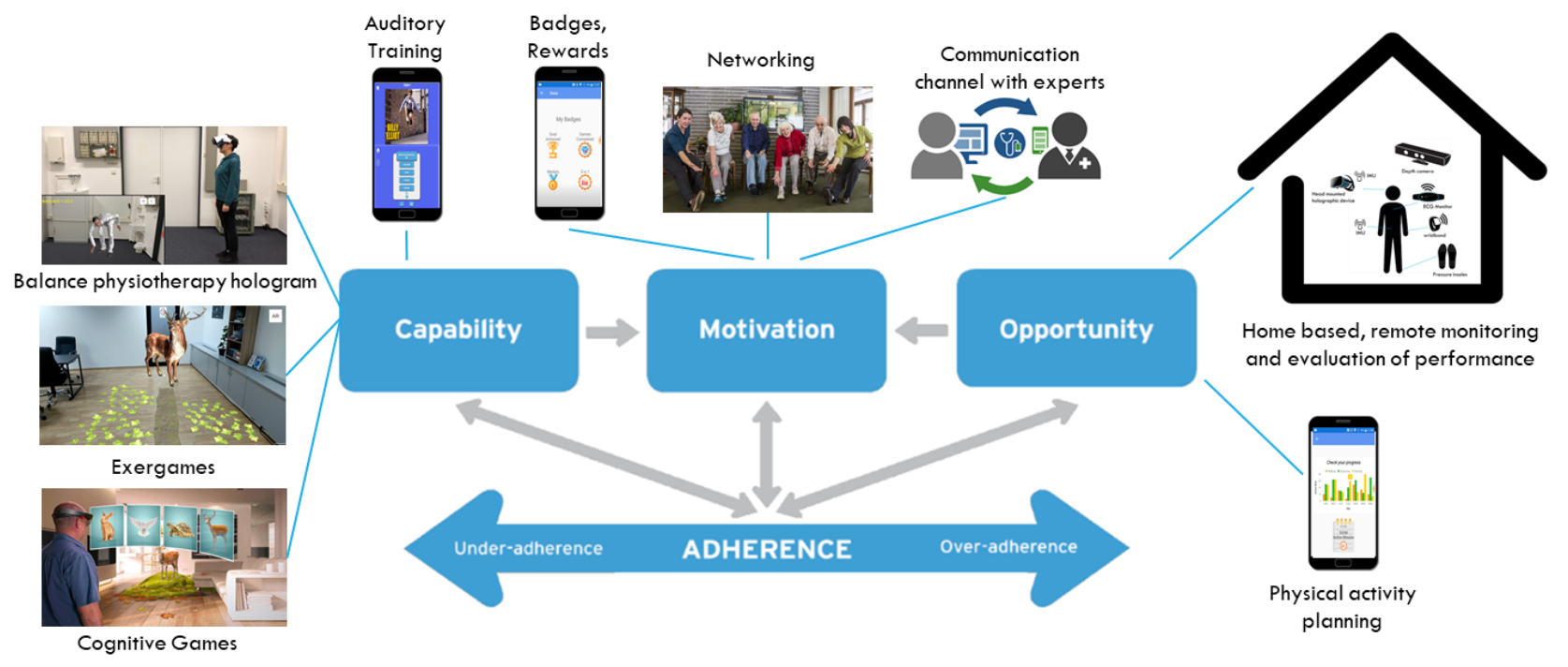

Figure 1 Linking the Holobalance modules to the COM-B model components.

balance, function, physical activity and confidence among the elderly [5; 7]. However, the question about what are the optimal methods for exercise selection, delivery, and progression is not yet conclusively answered. In fact, a study evaluating the Falls Management Exercise Programme (FaME), which is a 36 or 24week group-based, community delivered multisensory balance programme for older adults who fall, reported low adherence: only $31 \%$ of participants completed at least $75 \%$ of classes and home exercises over the 24-week programme [8;20]. On the other hand, in a study with the modified OTAGO exercise classes, supplemented with individualised, supervised home-based rehabilitation consisting of multisensory balance exercises, the adherence was $70 \%$ and the effectiveness as assessed with the Functional Gait Assessment (FGA) compared with usual practise being very promising [9]. Duration of the programmes and motivation provided by each are the two main reasons behind adherence.

It is generally accepted that long term maintenance of the effects of any home-based exercise programme depends on long term commitment from community-dwelling older adults, with exercise compliance decreasing over time [15]. The Holobalance platform is a hologram based technological solution that aims to provide personalised virtual coaching, as well as motivation for physical exercise performance for older adults at risk of falls. Holobalance has adopted a model proposing that 'behaviour' is part of an interacting system involving 'capability', 'opportunity', as well as 'motivation', i.e. the so called COM-B model [12].

\section{The Holobalance Platform}

The COM-B is a psychological model of behaviour change that can be used to identify factors related to successful behavioural change and specify targets to help modify health-related behaviour. It has been developed after extensive consultation with experts and practitioners of behavioural change.

The model posits that the interaction between Capability, Opportunity and Motivation (COM) causes the changes in Behaviour (B). Capability is the "individual's psychological and physical capacity to engage in the activity concerned". Opportunity includes the "factors that lie outside the individual that make the behaviour possible or prompt it". Motivation includes Reflective Motivation (evaluations, intentions and plans) and Automatic Motivation (emotions and impulses arising from learning and innate dispositions). Figure 1 shows how the Holobalance modules contribute to the COM-B components in order to achieve adherence to the intervention which is the objective of Holobalance.

The main interactive modules of Holobalance for achieving the behavioural change through a new user experience include:

1. The Balance Physiotherapist Hologram that interacts with the user, guiding him through the whole multisensory balance rehabilitation regime. Different hologram-based training prototypes are developed. Following an iterative approach, these prototypes are being evaluated and redesigned until the required performance metrics (effectiveness, efficiency, joy of use) are achieved. The hologram avatar is selected by the user to increase the affective and immersive characteristics of the interaction. The hologram is projected through a head mounted device with a smartphone embedded on it. It interacts with the user in real time by exchanging messages with the sensor environment that continuously monitors and evaluates the performance of exercises in order to increase the safety by prompting the user to correct positions or motions that threaten their balance, and improve the performance in case the execution is poor. After each exercise the hologram checks whether symptoms have been provoked and to what extent, 
Achieving Adherence in Home-Based Rehabilitation with Novel

Human Machine Interactions that Stimulate Community-Dwelling

PETRA'19, June, 2019, Rhodes, Greece

Older Adults

Table 1 Links between the components of the 'COM-B' model and the Holobalance intervention functions

\begin{tabular}{|c|c|c|c|c|c|c|c|}
\hline $\begin{array}{l}\text { Model of } \\
\text { behaviour } \\
\text { sources }\end{array}$ & $\begin{array}{c}\text { Education } \\
\text { Sources will } \\
\text { be provided } \\
\text { through the } \\
\text { patient app } \\
\text { The hologram } \\
\text { will provide } \\
\text { instructions } \\
\text { and intervene } \\
\text { when } \\
\text { necessary } \\
\text { (poor or } \\
\text { dangerous } \\
\text { performance) }\end{array}$ & $\begin{array}{l}\text { Persuasion } \\
\text { Daily feedback } \\
\text { from the } \\
\text { hologram } \\
\text { Weekly } \\
\text { message } \\
\text { exchange } \\
\text { between the } \\
\text { therapist and } \\
\text { the user }\end{array}$ & $\begin{array}{l}\text { Incentivization } \\
\text { Individualised } \\
\text { goal setting } \\
\text { with shared } \\
\text { decision } \\
\text { making } \\
\text { Collection of } \\
\text { badges, } \\
\text { communicated } \\
\text { through virtual } \\
\text { communities } \\
\text { and social } \\
\text { media }\end{array}$ & \begin{tabular}{|c} 
Training \\
Imparting skills, \\
especially balance, \\
and reducing \\
symptoms is the \\
core of the \\
intervention
\end{tabular} & $\begin{array}{l}\text { Environmental } \\
\text { restructuring } \\
\text { The home-based } \\
\text { approach and the } \\
\text { technological } \\
\text { elements are } \\
\text { essentially } \\
\text { changing the } \\
\text { context of the } \\
\text { intervention }\end{array}$ & \begin{tabular}{|c|} 
Modelling \\
The hologram will \\
display the correct \\
execution \\
providing an \\
example for users \\
to aspire to and \\
imitate
\end{tabular} & $\begin{array}{l}\text { Enablement } \\
\text { Overall, the } \\
\text { intervention aims } \\
\text { to increase } \\
\text { opportunities for } \\
\text { balance } \\
\text { rehabilitation and } \\
\text { reduce barriers } \\
\text { related to lack of } \\
\text { resources (costs, } \\
\text { experts } \\
\text { availability) }\end{array}$ \\
\hline $\begin{array}{l}\text { Physical } \\
\text { Capability }\end{array}$ & $\sqrt{ }$ & $\sqrt{ }$ & & $\sqrt{ }$ & & $\sqrt{ }$ & $\sqrt{ }$ \\
\hline $\begin{array}{l}\text { Psychological } \\
\text { Capability }\end{array}$ & $\sqrt{ }$ & & & $\sqrt{ }$ & & & $\sqrt{ }$ \\
\hline $\begin{array}{l}\text { Reflective } \\
\text { Motivation }\end{array}$ & $\sqrt{ }$ & $\sqrt{ }$ & $\sqrt{ }$ & $\sqrt{ }$ & & & $\sqrt{ }$ \\
\hline $\begin{array}{l}\text { Automatic } \\
\text { Motivation }\end{array}$ & & $\sqrt{ }$ & $\sqrt{ }$ & & $\sqrt{ }$ & $\sqrt{ }$ & \\
\hline $\begin{array}{l}\text { Physical } \\
\text { Opportunity }\end{array}$ & & & $\sqrt{ }$ & & $\sqrt{ }$ & & $\sqrt{ }$ \\
\hline $\begin{array}{l}\text { Social } \\
\text { Opportunity }\end{array}$ & & & $\sqrt{ }$ & & & & $\sqrt{ }$ \\
\hline
\end{tabular}

with the view to use this information, together with the sensor information, to inform exercise progression.

2. Exergames make use of aspects of video game design to engage citizens in their rehab and make it more accessible, which in turn encourages participation. Balance rehabilitation exercises are being gamified in order to keep the citizens compliant with the programme. Virtual objects and tasks are presented in an augmented, mixed reality, environment, projected through the head mounted device with the smartphone embedded on it to provide stimuli to the users. As above, the human machine interaction is based on real time evaluation of performance with wearable sensors. The user centric design makes imperative that exergames take into account the views of older people to ensure that the designs are appropriate, attractive and at the right level in terms of user experience.

3. The Cognitive Training Games are serious games used to stimulate cognitive skills (attention, memory, psychomotor abilities). Augmented mixed reality is the tool in order to overcome the problem with environmental spatial ability of individuals in the $3 \mathrm{D}$ simulations. The games can be parameterized to allow the modification of the pace, the density of stimuli and to enable or disable progression. They will register a number of indicators for data analysis and present them in correlation with progress in balance rehabilitation and physical activity.

4. The Auditory Training Tool trains the subject to perform a task (e.g. read a book, listen to instructions) in a noisy environment (e.g. cafeteria, public transport). The training material is presented through a mobile app by means of an adaptive procedure with preset performance criteria. Different competing stimuli such as babble noise (cafeteria type noise) are used. The training aims to improve speech in noise perception and auditory memory.

5. The ambient Motion Capture and Wearable Sensors environment has been developed for remotely monitoring, measuring and quantifying the execution of the physiotherapy exercises in real time at home, thus, reducing the need for follow-up visits in a clinical environment. Therefore, it is important that these sensors are accepted and usable by the older community dwelling citizens. The configuration includes a depth camera, a heart rate monitor, two IMUs in the 
lumbar and in the head and pressure insoles. This module informs the Balance Physiotherapy Hologram and the Exergames to provide real time feedback and to improve the human machine interaction through increased responsiveness and zero latency.

6. The Physical Activity Planning App apart from enabling activity monitored with an activity tracker, will also be used for connection and networking with virtual communities of users and competition as means of motivation. Educational sources for balance disorders and intervention addressing them will be available in the app. The module quantifies the physical activities performed in terms of steps, calories, active and sedentary periods. It enables both shared (citizen and physio) goal setting and individualised (only citizen) goal setting. Badges and rewards for achievements in exergames, cognitive games, vestibular rehabilitation therapy and activity goals will be available through this mobile app.

In Table 1, the links between the components of the 'COM-B' model and the Holobalance intervention functions are further analysed.

\section{Conclusions}

The Holobalance intervention has some unique characteristics: it is based on the established COM-B psychological model of behavior change and it evaluates the acceptance and feasibility of holograms as physiotherapist surrogates. It also adopts exergames, the acceptability and usability of which is already at a good level among older users, and serious games which is another topic of growing interest $[11 ; 13]$. The remote, unobtrusive, objective, real time and automated evaluation of performance is another challenge that enhances the human machine interaction, while mobile apps for auditory training and promotion of physical activity complement the needs of community dwelling citizens with balance disorders. The definition of personalised programmes combining these tasks in daily sessions for effective balance rehabilitation will be the scope of a multicentre, proof of concept study, in London, Athens and Freiburg.

\section{ACKNOWLEDGMENTS}

This work has received funding from the European Union's Horizon 2020 research and innovation programme under grant agreement No 769574.

\section{REFERENCES}

[1] Agrawal, Y., Carey, J.P., Della Santina, C.C., Schubert, M.C., and Minor, L.B. 2009. Disorders of balance and vestibular function in US adults: data from the National Health and Nutrition Examination Survey, 2001-2004. Arch Intern Med $\begin{array}{lllll}169, & 10 & \text { (May } & 25 \text { ), } & \text { 938-944. }\end{array}$ http://dx.doi.org/10.1001/archinternmed.2009.66.

[2] Bigelow, R.T., Semenov, Y.R., Du Lac, S., Hoffman, H.J., and Agrawal, Y. 2016. Vestibular vertigo and comorbid cognitive and psychiatric impairment: the 2008 National Health Interview Survey. J Neurol Neurosurg Psychiatry 87, 4 (Apr), 367-372. DOI: http://dx.doi.org/10.1136/jnnp-2015-310319.

[3] Cali, C.M. and Kiel, D.P. 1995. An epidemiologic study of fall-related fractures among institutionalized older people. J Am Geriatr Soc 43, 12 (Dec), 1336-1340.
[4] Clemson, L., Fiatarone Singh, M.A., Bundy, A., Cumming, R.G., Manollaras, K., O'loughlin, P., and Black, D. 2012. Integration of balance and strength training into daily life activity to reduce rate of falls in older people (the LiFE study): randomised parallel trial. BMJ : British Medical Journal 345, e4547. DOI: http://dx.doi.org/10.1136/bmj.e4547.

[5] Cyarto, E.V., Brown, W.J., Marshall, A.L., and Trost, S.G. 2008. Comparative effects of home- and group-based exercise on balance confidence and balance ability in older adults: cluster randomized trial. Gerontology 54, 5, 272-280. DOI: http://dx.doi.org/10.1159/000155653.

[6] Hartholt, K.A., Van Beeck, E.F., Polinder, S., Van Der Velde, N., Van Lieshout, E.M., Panneman, M.J., Van Der Cammen, T.J., and Patka, P. 2011. Societal consequences of falls in the older population: injuries, healthcare costs, and longterm reduced quality of life. J Trauma 71, 3 (Sep), 748-753. DOI http://dx.doi.org/10.1097/TA.0b013e3181f6f5e5.

[7] Hill, K.D., Hunter, S.W., Batchelor, F.A., Cavalheri, V., and Burton, E. 2015 Individualized home-based exercise programs for older people to reduce falls and improve physical performance: A systematic review and meta-analysis.

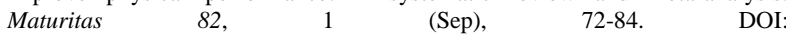
http://dx.doi.org/10.1016/j.maturitas.2015.04.005.

[8] Iliffe, S., Kendrick, D., Morris, R., Masud, T., Gage, H., Skelton, D., Dinan, S., Bowling, A., Griffin, M., Haworth, D., Swanwick, G., Carpenter, H., Kumar, A., Stevens, Z., Gawler, S., Barlow, C., Cook, J., and Belcher, C. 2014. Multicentre cluster randomised trial comparing a community group exercise programme and home-based exercise with usual care for people aged 65 years and over in primary care. Health Technol Assess 18, 49 (Aug), vii-xxvii, 1-105. DOI: http://dx.doi.org/10.3310/hta18490.

[9] Liston, M.B., Alushi, L., Bamiou, D.E., Martin, F.C., Hopper, A., and Pavlou, M. 2014. Feasibility and effect of supplementing a modified OTAGO intervention with multisensory balance exercises in older people who fall: a pilot randomized controlled trial. Clin Rehabil 28, 8 (Aug), 784-793. DOI: http://dx.doi.org/10.1177/0269215514521042.

[10] Liston, M.B., Bamiou, D.E., Martin, F., Hopper, A., Koohi, N., Luxon, L., and Pavlou, M. 2014. Peripheral vestibular dysfunction is prevalent in older adults experiencing multiple non-syncopal falls versus age-matched non-fallers: a pilot study. Age Ageing 43, 1 (Jan), 38-43. DOI: http://dx.doi.org/10.1093/ageing/aft129.

[11] Mansor, N.S., Chow, C.M., and Halaki, M. 2019. Cognitive effects of video games in older adults and their moderators: a systematic review with metaanalysis and meta-regression. Aging Ment Health(Feb 20), 1-16. DOI: http://dx.doi.org/10.1080/13607863.2019.1574710.

[12] Michie, S., Van Stralen, M.M., and West, R. 2011. The behaviour change wheel: A new method for characterising and designing behaviour change interventions. Implementation Science $6, \quad 1 \quad(2011 / 04 / 23), \quad 42 . \quad$ DOI http://dx.doi.org/10.1186/1748-5908-6-42.

[13] Nawaz, A., Skjaeret, N., Helbostad, J.L., Vereijken, B., Boulton, E., and Svanaes, D. 2016. Usability and acceptability of balance exergames in older adults: A scoping review. Health Informatics $J$ 22, 4 (Dec), 911-931. DOI: http://dx.doi.org/10.1177/1460458215598638.

[14] Palumbo, P., Palmerini, L., Bandinelli, S., and Chiari, L. 2015. Fall Risk Assessment Tools for Elderly Living in the Community: Can We Do Better? Plos One 10, 12, e0146247-e0146247. DOI http://dx.doi.org/10.1371/journal.pone.0146247.

[15] Picorelli, A.M., Pereira, L.S., Pereira, D.S., Felicio, D., and Sherrington, C. 2014 Adherence to exercise programs for older people is influenced by program characteristics and personal factors: a systematic review. J Physiother 60, 3 (Sep), 151-156. DOI: http://dx.doi.org/10.1016/j.jphys.2014.06.012.

[16] Roe, B., Howell, F., Riniotis, K., Beech, R., Crome, P., and Ong, B.N. 2009 Older people and falls: health status, quality of life, lifestyle, care networks, prevention and views on service use following a recent fall. J Clin Nurs 18, 16 (Aug), 2261-2272. DOI: http://dx.doi.org/10.1111/j.1365-2702.2008.02747.x.

[17] Rubenstein, L.Z. and Josephson, K.R. 2002. The epidemiology of falls and syncope. Clin Geriatr Med 18, 2 (May), 141-158.

[18] Stenhagen, M., Ekstrom, H., Nordell, E., and Elmstahl, S. 2014. Accidental falls, health-related quality of life and life satisfaction: a prospective study of the general elderly population. Arch Gerontol Geriatr 58, 1 (Jan-Feb), 95-100. DOI http://dx.doi.org/10.1016/i.archger.2013.07.006.

[19] Thomas, S., Mackintosh, S., and Halbert, J. 2010. Does the 'Otago exercise programme' reduce mortality and falls in older adults?: a systematic review and meta-analysis. Age Ageing 39, 6 (Nov), 681-687. DOI http://dx.doi.org/10.1093/ageing/afq102.

[20] Yeung, P.Y., Chan, W., and Woo, J. 2015. A community-based Falls Management Exercise Programme (FaME) improves balance, walking speed and reduced fear of falling. Prim Health Care Res Dev 16, 2 (Apr), 138-146. DOI: http://dx.doi.org/10.1017/s1463423614000024.

[21] Yoshida-Intern, S. 2007. A global report on falls prevention - Epidemiology of falls, WHO Ed. 